\title{
Übersicht zu Kapital und Haftung
}

Die nachfolgende Übersicht stellt schematisch die wichtigsten Rechtsformen dar im Vergleich der Kategorien Kapital, Mindesteinzahlung und Haftung sowie Geschäftsführung und Handelsregistereintragung:

Überblick über die Rechtsformen

\begin{tabular}{l|l|l|l|l|l}
\hline & GbR & OHG & KG & GmbH & AG \\
\hline $\begin{array}{l}\text { Minimum- } \\
\text { Gesellschafter }\end{array}$ & 2 & 2 & $\begin{array}{l}2(1 \text { haftungs- } \\
\text { beschränkt })\end{array}$ & 1 & 1 \\
\hline Minimum-Kapital & Keins & Keins & $\begin{array}{l}\text { Beachte Kom- } \\
\text { manditeinlage }\end{array}$ & $€ 25.000,00$ & $€ 50.000,00$ \\
\hline Minimum-Einzahlung & Keine & Keine & Keine & $\begin{array}{l}25 \%, \text { mindes- } \\
\text { tens } € 12.500,00\end{array}$ & $25 \%$ \\
\hline $\begin{array}{l}\text { Haftung des } \\
\text { Gesellschafters }\end{array}$ & $\begin{array}{l}\text { Unbe- } \\
\text { schränkt }\end{array}$ & $\begin{array}{l}\text { Unbe- } \\
\text { schränkt }\end{array}$ & $\begin{array}{l}\text { IdR auf Einlage } \\
\text { beschränkt }\end{array}$ & Keine & Keine \\
\hline Geschäftsführung & $\begin{array}{l}\text { Alle Gesell- } \\
\text { schafter }\end{array}$ & $\begin{array}{l}\text { Alle Gesell- } \\
\text { schafter }\end{array}$ & $\begin{array}{l}\text { Komplementär } \\
\text { (phG) }\end{array}$ & Geschäftsführer & Vorstand \\
\hline
\end{tabular}

